\title{
Sleep Quality and Quantity in Intensive Care Unit Patients: A Cross-sectional Study
}

\author{
Ramavath Devendra Naik ${ }^{12}$, Kartik Gupta², Manish Soneja ${ }^{2}$, Arunmozhimaran Elavarasi²,3, V. Sreenivas ${ }^{4}$, Sanjeev Sinha ${ }^{2}$ \\ Departments of ${ }^{1}$ Medical Oncology, ${ }^{2}$ Medicine, ${ }^{3}$ Neurology and ${ }^{4}$ Biostatistics, All India Institute of Medical Sciences, New Delhi, India
}

\section{Abstract}

Introduction: Lack of restorative sleep and altered sleep-wake cycle is a frequent problem among patients admitted to the Intensive Care Unit (ICU). This study was conducted to estimate the prevalence of poor sleep and patient's perspective of factors governing poor sleep in the ICU. Materials and Methods: A cross-sectional study was performed in medical ICU of a tertiary care hospital. A total of 32 patients admitted to the ICU for at least $24 \mathrm{~h}$ were recruited. A 72-h actigraphy was done followed by a subjective assessment of sleep quality by the Richards-Campbell Sleep Questionnaire (RCSQ). Patient's perspective of sleep quality and quantity and possible risk factors for poor sleep were recorded. Results: Poor sleep (defined as RCSQ $<50$, sensitivity $88 \%$ and specificity $87 \%$ ) was found in 15 out of the 32 patients (47\%). The prevalence of poor sleep was higher among patients on mechanical ventilation $(n=15)(66.7 \% \mathrm{vs.} 33.3 \%, P<0.05)$. Patients with poor sleep had higher age (median age [in years] 42.8 vs. $31.4, P=0.008$ ), acute physiology, and chronic health evaluation II score (mean $14 \pm 5.15$ vs. $9.3 \pm 5.64, P=0.02)$, SAPS 3 score $(62.7 \pm 8.9$ vs. $45.6 \pm 10.5, P \leq 0.0001)$, and worse actigraphy parameters. Only $55.63 \%$ of total sleep time was in the night (2200-0600). All patients had discomfort from indwelling catheters and suctioning of endotracheal tubes. All patients suggested that there be a minimum interruption in the sleep for interventions or medications. Conclusion: There is a high prevalence of poor sleep among patients admitted to the ICU. There is a dire need to minimize untimely interventions and design nonpharmacological techniques to allow patients to sleep comfortably.

Keywords: Actigraphy, Intensive Care Unit, Richards-Campbell Sleep Questionnaire, sleep quality

\section{INTRODUCTION}

Sleep is a naturally occurring periodic, reversible state of reduced consciousness, and response to external stimuli. Normal human sleep consists four to six 90-100 min blocks, during which nonrapid eye movement and rapid eye movement (REM) sleep alternate in a cyclical fashion accounting for a total sleep duration of $7-8 \mathrm{~h} /$ night. $^{[1]}$

Sleep is an indispensable physiological need often underestimated and disregarded especially in critically ill patients. ${ }^{[2-4]}$ Sleep in them is highly fragmented; therefore, they lack deep restorative REM sleep. Around $38.5 \%$ of the patients who survived critical illness and were on mechanical ventilation (MV) for at least $48 \mathrm{~h}$ reported not being able to sleep well, $40 \%$ of the study group remembered frequent awakenings in the night, and $35 \%$ recalled having had difficulty falling asleep during their Intensive Care Unit (ICU) admission. ${ }^{[5]}$ Sleep deprivation has been associated with the release of inflammatory cytokines, worse cardiovascular outcomes,

\begin{tabular}{|l|l|}
\hline \multicolumn{2}{|c|}{ Access this article online } \\
\hline Quick Response Code: & Website: \\
\hline & www.ijccm.org \\
\cline { 2 - 2 } & \\
\hline
\end{tabular}

poorer immunological response, etc. ${ }^{[6]}$ Sleep disruption induces a catabolic state, impairs cellular and humoral immune response, ${ }^{[7]}$ and causes respiratory dysfunction due to muscle fatigue and central respiratory. ${ }^{[8]}$ Sleep disturbances are known to impair consolidation of memory and cognitive function. ${ }^{[9-13]}$

Various factors implicated to cause sleep deprivation in ICU setting, such as delirium because of organic causes, underlying disease state, noise, and change in environment, MV and sedatives, unavailability of familial faces, etc. ${ }^{[3,10,14,15]}$

Polysomnography (PSG) is the gold standard for measuring sleep; but in the ICU setting, it is cumbersome and impractical. ${ }^{[13,16]}$ Actigraphy, which is a validated substitute

Address for correspondence: Dr. Kartik Gupta, Department of Medicine, All India Institute of Medical Sciences, New Delhi - 110 029, India. E-mail: kartikgupta.aiims@gmail.com

This is an open access journal, and articles are distributed under the terms of the Creative Commons Attribution-NonCommercial-ShareAlike 4.0 License, which allows others to remix, tweak, and build upon the work non-commercially, as long as appropriate credit is given and the new creations are licensed under the identical terms.

For reprints contact: reprints@medknow.com

How to cite this article: Naik RD, Gupta K, Soneja M, Elavarasi A, Sreenivas V, Sinha S. Sleep quality and quantity in intensive care unit patients: A cross-sectional study. Indian J Crit Care Med 2018;22:408-14. 
for PSG, ${ }^{[17]}$ has been widely used in the ICU due to its low cost and minimally invasive nature. ${ }^{[18-20]}$

The primary objective of our study was to assess the quantity and quality of sleep in patients admitted to the ICU using actigraphy and Richards-Campbell Sleep Questionnaire (RCSQ) respectively. Our secondary objective was to know patient's perspective of factors related to poor sleep.

\section{Materials and Methods}

A cross-sectional study was conducted in an eight-bed adult medical ICU of a tertiary care hospital in North India. The ICU caters to patients with sepsis, poisoning, multisystem dysfunction, and acute respiratory distress syndrome; there is a separate ICU for cardiology, gastroenterology, neurology, postoperative, and trauma patients which were not included as part of this study. There are eight nursing officers on duty at a time, with the patient: nurse ratio varying from $2: 1$ to $3: 1$ depending on the workload. There are two house physicians on duty at a time, with rounds being conducted once daily by the consultant physician, usually between 0930 and 1130 . There is no barrier to compartmentalize each patient bed. There were only two beds by the window and no nonpharmacological aid-like earplugs and soothing mask available. Entry of one family relative was allowed every day between 1700 and 1800. Patients in the age group of 18-60 years who were able to give informed written consent and admitted for at least $24 \mathrm{~h}$ in ICU before actigraphy were included in the study. If intubated at the time of admission, s/he was recruited $24 \mathrm{~h}$ after extubation. Patients were screened by confusion assessment method-ICU questionnaire ${ }^{[21]}$ for delirium, Modified Berlin Questionnaire $^{[22]}$ for premorbid sleep illness(s) and Epworth Sleepiness Score ${ }^{[23]}$ for obstructive sleep apnea; those tested positive or found to be at an elevated risk were excluded. In addition, those with kidney disease and past or current history of the cerebrovascular accident were excluded as they are some of the known risk factors that alter sleep-wake cycle. ${ }^{[24,25]}$ Ethical clearance was obtained from the Institutional ethics committee. Data were collected from January 2014 to June 2014.

\section{Evaluation of the patients at the baseline}

After admission to the ICU, data were collected regarding clinical and laboratory parameters at the time of admission; acute physiology and chronic health evaluation II (APACHE II) score, ${ }^{[26]}$ and simplified acute physiology score 3 (SAPS 3) ${ }^{[27]}$ scores were calculated (higher score associated with higher chances of mortality). After $24 \mathrm{~h}$ of ICU admission, patients were re-assessed on a routine basis and if inclusion criteria were met, 72-h actigraphy was done. After actigraphy study, assessment of sleep quality was done using RCSQ. ${ }^{[28]}$ The researcher was not aware of the actigraphy results of the patient. Information regarding factors causing discomfort during ICU stay was collected with a preformed questionnaire. Individual suggestions to improve sleep quality in the ICU were also taken from the participants.

\section{Actigraphy}

The actigraph SOMNOwatch ${ }^{\mathrm{TM}}$ was worn on the nondominant arm by the participant. The activity was measured in epochs of $15 \mathrm{~s}$ and plotted as an actigraphy profile. The watch has seven channels including six internal channels (body position, three activity sensors, ambient light and patient marker, and one external signal input (AUX). It has a 12 analog to digital converter, with an adjustable sampling rate of $256 / \mathrm{s}$ to $1 / \mathrm{s}$ and adjustable storage rates of $1 / 120 \mathrm{~s}$ to $256 / \mathrm{s}$. It has internal data storage of $8 \mathrm{MB}$, has a size of $45 \mathrm{~mm} \times 16 \mathrm{~mm}$ and weighs $30 \mathrm{~g}$ (including battery). DOMINOlight 1.3 .0 version was used for analysis.

\section{Scoring and sleep determination}

Automatic scoring using the event marker points (lights off and lights on) was checked by the same scorer to determine the participants' time in bed (TIB). Usually, through the integrated light sensor, the relevant measurement period (TIB) is determined. However, this method cannot be applied in ICU because the intensity of light is different from time to time and does not correlate with the sleeping periods of the patient. Therefore, patients were asked to press the marker button just before going to sleep and immediately after waking up from sleep. This was marked as lights off and lights on, respectively. The time between lights off and lights on was taken as total TIB. Based on this, actigraph gives us other sleep parameters [Listed in Table 1]. Usually, the circadian rhythm will be automatically calculated by actigraph by the light input sensor. But since, this was irrelevant in the ICU, we calculated circadian rhythm by dividing $24 \mathrm{~h}$ into three 8 h periods, (2200-0600, 0600-1400, and 1400-2200). The total sleep time during each phase was calculated and thus the distribution of sleep epochs was determined.

The overall perception of the sleep was collected by asking the question "How was your sleep during the ICU stay?" with a dichotomous response collected, i.e. either good or poor. Since judgment by the patient is the best way to assess sleep, we considered the overall self-perception of sleep as the

\begin{tabular}{ll}
\hline Table 1: Definition of various actigraphy parameters \\
\hline Actigraphy Parameter & Definition \\
\hline Lights off & Time at which subject went to bed \\
End (lights on) & The time the subject wakes up \\
TIB & Time in minutes, between light off and sleep \\
& end (lights on) \\
SOL & $\begin{array}{l}\text { Interval in minutes, between light off and } \\
\text { sleep start }\end{array}$ \\
TST & Sum, in minutes, of all sleep epochs between \\
& sleep onset and sleep end (lights off) \\
WASO & Sum, in minutes, of all wake epochs between \\
& sleep onset and sleep end \\
Sleep efficiency (\%) & The ratio of the total sleep time to time in \\
& bed multiplied by 100 \\
Number of awakenings & The number of wake episodes $>5$ min \\
\hline
\end{tabular}

TIB: Time in bed; SOL: Sleep onset latency; TST: Total sleep time; WASO: Wake after sleep onset 
standard. Richards Campbell sleep questionnaire (RCSQ) was then applied to objectively evaluate sleep quality. It consists of a 5-item questionnaire evaluating sleep depth, latency, number of awakenings, efficiency, and quality (with a sixth parameter, noise added in modified RCSQ). The technique is the same as described by Kamdar et al. ${ }^{[29]}$

Based on these qualitative and quantitative answers, we generated a cut in value for RCSQ score. Based on this new standard of RCSQ score, we defined the poor sleep as RCSQ score below the derived cut off value.

\section{Sleep disturbance definition}

A total RCSQ score of $\geq 50$ was used to define good sleep (sensitivity $88.24 \%$, specificity $86.67 \%$ ) (receiver operating characteristic [ROC] area- $0.92,95 \%$ confidence interval [CI]). Patients with total RCSQ score $<50$ were considered to have poor sleep.

\section{Statistical analysis}

Statistical analysis was performed using STATA version 12.0 (STATA Corporation, College Station Road, Houston, Texas, USA). The data analyzer was aware of the patient group. A sample size of convenience was taken. Two-tailed $P<0.05$ was considered statistically significant. The statistical tests used are the same as listed by the author(s) previously. ${ }^{[30]}$

\section{RESULTS}

A total of seventy patients were screened, out of whom forty fulfilled the criteria of the study. Of the patients who fulfilled the inclusion criteria, 35 gave informed consent. Of the 35 patients, three could not complete the study, because of early transfer out from ICU to the ward [Figure 1]. The characteristics of the enrolled patients are given in Table 2 . The mean age of the study population was $36.8 \pm 12.7$ years.
There were 18 males and 14 females in the study population. The mean APACHE II score of the study group was $11.5 \pm 5.8$.

\section{Actigraphy}

The actigraphy parameters among those with good sleep (RCSQ score $\geq 50 \mathrm{~mm}$ ) and with poor sleep (RCSQ score $<50 \mathrm{~mm}$ ) are shown in Table 3. Although TIB and TST did not differ in the two groups, there was a significant difference in sleep efficiency, WASO, and a total number of awakenings.

\section{Richards-Campbell Sleep Questionnaire}

The mean RCSQ score of our study population was $51.6 \pm 13.5 \mathrm{~mm}$. An RCSQ score of $\geq 50 \mathrm{~mm}$ had a sensitivity of $88.2 \%$ and specificity of $86.7 \%$ in determining patients with good sleep as assessed by patient perception (ROC area 0.91, CI 95\%) [Figure 2]. Patients with RCSQ

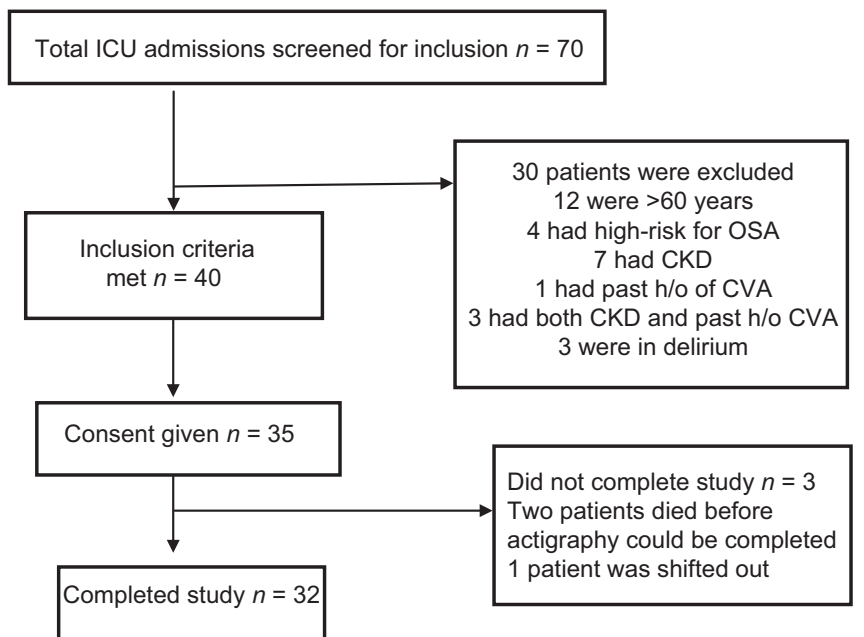

Figure: 1: Study flow diagram

\begin{tabular}{|c|c|c|c|c|}
\hline Variable & Mean $\pm S D^{*}$ or median $(\mathrm{IQR})^{\#}(n=32)$ & Good sleep $(n=17)$ & Poor sleep $(n=15)$ & $P$ \\
\hline Age (years) & $36.8 \pm 12.7$ & $31.4 \pm 12.3$ & $42.8 \pm 10.6$ & 0.008 \\
\hline Male gender $(\%)$ & $18(56.3)$ & $9(53)$ & $9(60)$ & 0.69 \\
\hline MV $(\%)$ & $15(47)$ & $5(29.4)$ & $10(66.7)$ & 0.04 \\
\hline APACHE II score & $11.5 \pm 5.8$ & $9.3 \pm 5.6$ & $14 \pm 5.2$ & 0.02 \\
\hline SAPS 3 score & $53.7 \pm 13$ & $45.6 \pm 10.5$ & $62.7 \pm 8.9$ & $<0.001$ \\
\hline BMI $\left(\mathrm{kg} / \mathrm{m}^{2}\right)$ & $23.3 \pm 3.6$ & $23.6 \pm 3.5$ & $22.9 \pm 3.8$ & 0.63 \\
\hline $\mathrm{pH}$ & $7.35 \pm 0.08$ & $7.38 \pm 0.85$ & $7.32 \pm 0.08$ & 0.03 \\
\hline $\mathrm{pO}_{2}(\mathrm{mmHg})$ & $95.6 \pm 32.4$ & $90.3 \pm 20.9$ & $101.5 \pm 42$ & 0.33 \\
\hline $\mathrm{pCO}_{2}(\mathrm{mmHg})$ & $40.4 \pm 14.1$ & $39.1 \pm 11.4$ & $41.9 \pm 16.9$ & 0.58 \\
\hline MAP (mmHg) & $78.1 \pm 22.2$ & $80.2 \pm 15.2$ & $75.8 \pm 28.6$ & 0.49 \\
\hline Serum lactate $(\mathrm{mmol} / \mathrm{l})$ & $1.9(1.2-3.3)$ & $1.8(1-2.5)$ & $2.8(1.4-3.4)$ & 0.35 \\
\hline Urea $(\mathrm{mg} / \mathrm{dl})$ & $48.5(29.5-72.5)$ & $41(25-55)$ & $59(31-75)$ & 0.17 \\
\hline Creatinine (mg/dl) & $1.2(0.8-2.2)$ & $0.9(0.8-1.5)$ & $1.3(0.9-2.5)$ & 0.26 \\
\hline Total bilirubin (g/dl) & $1(0.6-2.1)$ & $0.8(0.6-1.1)$ & $1.6(0.6-3.5)$ & 0.03 \\
\hline SGOT (IU/l) & $41(33-72)$ & $36(33-56)$ & $53(35-133)$ & 0.13 \\
\hline SGPT (IU/l) & $36(17.5-65)$ & $34(18-41)$ & $42(15-93$ & 0.32 \\
\hline
\end{tabular}

*For data following normal distribution, ${ }^{*}$ For data following nonnormal distribution. MV: Mechanical ventilation; MAP: Mean arterial pressure;

SGOT: Serum glutamate ornithine transferase; SGPT: Serum glutamate pyruvate transferase; APACHE II: Acute physiology and chronic health evaluation; SAPS 3: Simplified acute physiology score; IQR: Interquartile range; SD: Standard deviation; BMI: Body mass index 
score $\leq 50 \mathrm{~mm}$ were considered to have poor sleep. According to this definition, the prevalence of poor sleep among studied patients in medical ICU (MICU) 46.8\% (15/32) [Table 4].

A sixth parameter used in previous studies along with the five parameters of RCSQ was noise. The mean modified RCSQ score was $51.2 \pm 12.7 \mathrm{~mm}$. A cutoff score of $\geq 48 \mathrm{~mm}$ of modified RCSQ had a sensitivity $88.2 \%$ and specificity of $73.3 \%$ (ROC area 0.88 , CI: 95\%) in defining patients with good sleep. The prevalence of poor sleep by modified RCSQ score was $40.6 \%(13 / 32)$.

The patients with good sleep were younger than those with poor sleep (mean age $31.4 \pm 12.3$ vs. $42.8 \pm 10.6$ years, $P=0.008)$. There was no significant difference in perception of poor sleep with regards to gender distribution $(47.1 \%$ vs. $40.0 \%, P=0.69)$. A total of 15 patients $(46.9 \%)$ were mechanically ventilated during the ICU stay and had received sedative medication. The percentage of poor sleep was higher in patients who were mechanically ventilated, in comparison to those who were not $(66.7 \%$ vs. $33.3 \%$, $P=0.035)$. Patients with poor sleep had a significantly higher APACHE II score when compared to patients with good sleep $(14 \pm 5.2$ vs. $9.4 \pm 5.6, P=0.02)$. Similarly, patients with poor sleep had significantly higher SAPS 3 score when compared to patients with good sleep $(62.7 \pm 8.9$ vs. $45.6 \pm 10.5$,

\begin{tabular}{lcccc}
\hline Table 3: Actigraphy parameters \\
\hline Parameter/day & Mean \pm SD & $\begin{array}{c}\text { Poor sleep } \\
(\boldsymbol{n}=\mathbf{1 5})\end{array}$ & $\begin{array}{c}\text { Good sleep } \\
(\boldsymbol{n}=\mathbf{1 7})\end{array}$ & $\boldsymbol{P}$ \\
\hline TIB (min) & $669.4 \pm 114.8$ & $680 \pm 127.5$ & $660 \pm 105.1$ & 0.63 \\
TST (min) & $522.6 \pm 122.4$ & $515.2 \pm 141$ & $552.8 \pm 104.4$ & 0.39 \\
Wake duration (min) & $128.6 \pm 62.2$ & $156.2 \pm 69.1$ & $104.1 \pm 44.2$ & 0.02 \\
Sleep latency (min) & $14.4 \pm 10.6$ & $14.8 \pm 14.1$ & $14 \pm 6.7$ & 0.82 \\
Sleep efficiency (\%) & $80.6 \pm 7.8$ & $76.4 \pm 8.4$ & $84.4 \pm 4.9$ & 0.002 \\
WASO (min) & $113.3 \pm 60.0$ & $147.9 \pm 54.8$ & $82.9 \pm 47.2$ & 0.001 \\
Number of awakenings & $5.0 \pm 3.1$ & $6.9 \pm 2.8$ & $3.3 \pm 2.1$ & $<0.001$ \\
\hline SD: Standard deviation; TIB: Time in bed; TST: Total sleep time; & \\
WASO: Wake after sleep onset
\end{tabular}

$P<0.0001)$. Body Mass Index (BMI, in $\mathrm{kg} / \mathrm{m}^{2}$ ) in patients with good sleep was higher than patients with poor sleep; however, it was statistically insignificant $(23.62 \pm 3.5$ vs. $22.9 \pm 3.8, P>0.05)$. Except for total bilirubin and $\mathrm{pH}$, the hematological and biochemical parameters were comparable at the time of admission in patients with poor sleep and good sleep.

There was no significant difference in the median duration of hospital stay before actigraphy between those with poor and good sleep (8.4 days [interquartile range (IQR): 2.5-9.2] vs. 11 days [IQR: 5.8-19.8], $P>0.05$ ).

\section{Circadian rhythm and sleep disturbances}

Mean TST over three days was $11.4 \pm 4.1 \mathrm{~h}$; divided into the three periods of 2200-0600, 0600-1400 and 1400-2200 as $6.3 \pm 1.7 \mathrm{~h}, 2.7 \pm 1.1 \mathrm{~h}$ and $2.4 \pm 1.3 \mathrm{~h}$ respectively; showing that only $55.63 \%$ of TST was in the night (2200-0600). This pattern of altered sleep-wake cycle was found in both mechanically ventilated and other patients.

\section{Patient-perceived risk factors for poor sleep and suggestions}

Factors causing discomfort during the ICU stay were assessed and have been listed in Table 5. Indwelling catheters (central line, Foleys catheter, and nasogastric tube) and endotracheal tube suctioning were the most common factors causing maximum discomfort. Rounds conducted by the medical team were the least discomforting factor. The suggestions given by the study population to improve the ICU care are listed in Table 6.

\section{Discussion}

This study characterizes sleep quality and quantity using both qualitative and quantitative techniques in ICU patients. There was a high prevalence of poor sleep which was fragmented with altered sleep-wake cycle; more so among patients who were on mechanical ventilation. Despite recent

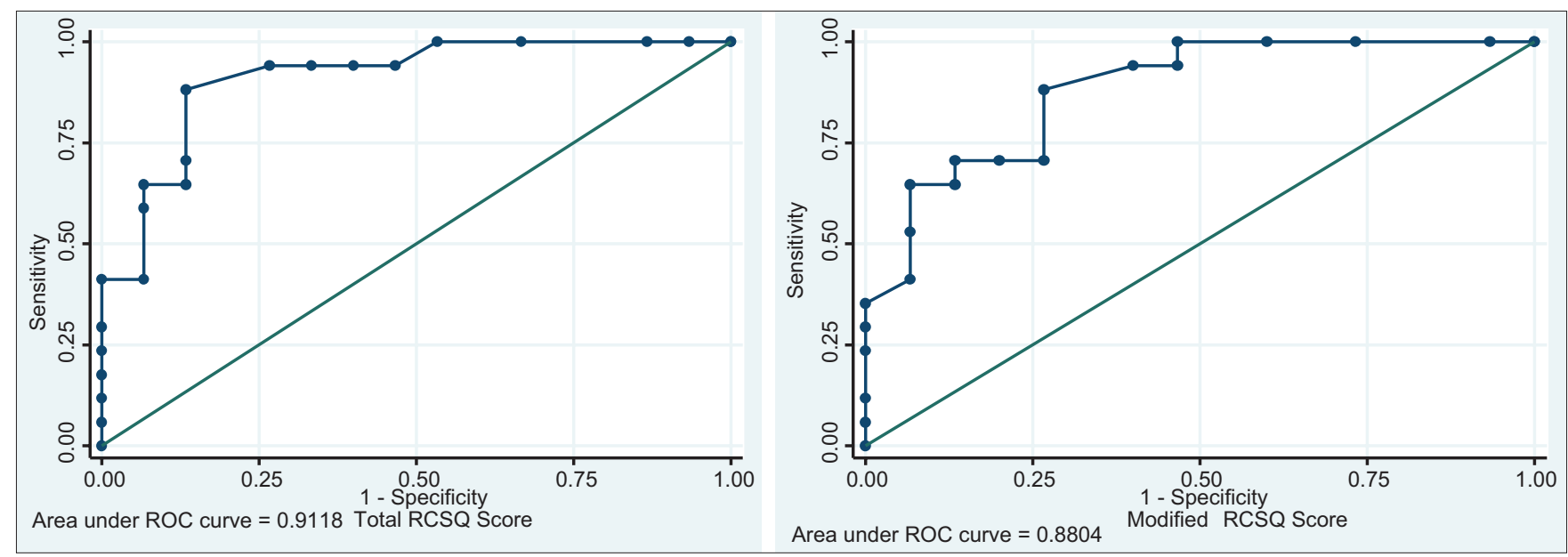

Figure 2: Receiver operating characteristic curve of total Richards-Campbell Sleep Questionnaire score and modified Richards-Campbell Sleep Questionnaire score 


\begin{tabular}{lc}
\hline $\begin{array}{l}\text { Table 4: Richards-Campbell Sleep Questionnaire } \\
\text { parameters }\end{array}$ & Mean \pm SD (mm) \\
\hline RCSQ parameter & $50 \pm 15.2$ \\
\hline Sleep depth & $54.1 \pm 17.6$ \\
Sleep latency & $46.1 \pm 16.2$ \\
Number of awakenings & $53.4 \pm 15.2$ \\
Returning to sleep & $54.2 \pm 15.0$ \\
Sleep quality & $51.6 \pm 13.5$ \\
Total RCSQ score (average of above 5 parameters) & $51.3 \pm 13.4$ \\
Noise & $51.2 \pm 12.7$ \\
Total modified RCSQ score (average of total & \\
RCSQ plus noise) & \\
\hline RCSQ: Richards-Campbell Sleep Questionnaire; SD: Standard deviation
\end{tabular}

\begin{tabular}{lc}
\hline Table 5: Factors associated with sleep disturbance \\
\hline Factors causing discomfort to the patients & $\begin{array}{c}\text { Percentage of } \\
\text { patients }(\boldsymbol{n}=\mathbf{3 2})\end{array}$ \\
\hline Indwelling catheters (Foleys catheter, NG tube) & 100 \\
Suctioning of endotracheal tube* & 100 \\
Diagnostic tests (X-ray, blood test) & 93.75 \\
Nursing care (bedding, bathing) & 93.75 \\
Invasive procedures & 93.75 \\
Lights on during the night time & 87.5 \\
Medication injection & 87.5 \\
Other patients in ICU & 78.1 \\
Time disorientation & 78.1 \\
Loud talking of the ICU team & 62.5 \\
Doctor rounds & 6.25 \\
\hline * $n=15$. ICU: Intensive Care Unit; NG: Nasogastric
\end{tabular}

Table 6: Suggestions from participants to improve sleep $(n=32)$

\begin{tabular}{lc}
\hline Suggestion (yes) & $\boldsymbol{n}(\mathbf{\%})$ \\
\hline No unnecessary interruption & $32(100)$ \\
Pain medication during ICU stay & $30(93.8)$ \\
Lights off in the night time & $30(93.8)$ \\
Clock in the ICU & $30(93.8)$ \\
Television in the ICU & $30(93.8)$ \\
Window bed & $28(87.5)$ \\
Music therapy during ICU stay & $25(78.1)$ \\
Sleeping pill wanted & $25(78.1)$ \\
More blankets & $20(62.5)$ \\
Low sound in ICU & $17(53.1)$ \\
Eye mask during sleep & $15(46.8)$ \\
Earplugs during sleep & $15(46.8)$ \\
\hline ICU: Intensive Care Unit
\end{tabular}

advances in critical care medicine and a lot of research showing adverse events related to sleep deprivation, this area has been tough to tackle with minimal improvement over the years.

While there is a high level of agreement between actigraphy and PSG in healthy participants ${ }^{[17]}$ a study done by Beecroft et al. ${ }^{[31]}$ in $14 \mathrm{MV}$ patients showed poor agreement between the two because of the high level of inactivity in patients who are critically ill. The accuracy using automatic threshold in the same study was only $51 \% .{ }^{[31]}$ Total sleep time correlation between actigraphy and PSG varies from 0.72 to $0.98 .{ }^{[32]}$ Mean TIB and TST were $11 \pm 2$ and $8.7 \pm 2$, respectively, reflecting that the patients were asleep one-third of the time. Although the duration of sleep was within normal range, it was fragment with frequent awakenings and alteration in circadian rhythm. Only $55.6 \%$ of TST was in the night (2200-0600). This altered sleep-wake cycle has been well-documented previously in ICU patients. ${ }^{[4,3,33]}$ This is reflective of the poor RCSQ score which is a subjective way of sleep assessment.

The mean score $(51.6 \pm 13.5 \mathrm{~mm})$ obtained was lower than the mean score obtained $(60 \pm 27 \mathrm{~mm})$ in Richard's original validation study in 70 male ICU patients. ${ }^{[28]}$ This is probably due to less sick patients included by Richard in the study group (none of the patients were on MV), who, therefore, required fewer procedures, indwelling catheters, and medication that are the major risk factors affecting sleep quality. In a study done in Sweden among 31 surgical patients admitted in the emergency ICU, mean RCSQ and modified RCSQ were $45.5 \mathrm{~mm}$ and $66.5 \mathrm{~mm}$, respectively. ${ }^{[34]}$ This study had a large number of patients $>75$ years of age $(8 / 31)$, and it is a well-known fact that perception of sleep quality decreased with advancing age. ${ }^{[35]}$ In another study among 104 postsurgical patients admitted in the ICU, mean RCSQ on the first postoperative night was $51.42 \mathrm{~mm} \cdot{ }^{[36]}$ Our study, was, however, conducted in a medical ICU, and therefore, the risk factors and the patient profile was different; the results, therefore, cannot be compared. Our results are similar to that reported by Kamdar et al., ${ }^{[29]}$ where mean RCSQ among 33 patients ( 92 paired responses over 137 patient-days) admitted in medicine ICU was $57( \pm 30) \mathrm{mm}$. while RCSQ is a standardized and easy way to subjectively assess sleep quality, application, and interpretation of RCSQ should be taken with a pinch of salt. In an interventional study done by Bourne et al. , $^{[37]} 20 \%$ patients were not able to complete RCSQ, primarily because of delirium. In another study ${ }^{[36]}$ among ICU patients, the failure rate of around $50 \%$ was observed.

Our results of worse sleep quality in higher APACHE II score was similar to the study done by Gabor et al. ${ }^{[38]}$ a shortened sleep time, reduced SWS and increased awakening index was seen in patients with higher APACHE II score compared to healthy participants. Fanfulla et al.$^{[39]}$ found high SAPS score and alkalosis to be important causes of sleep disturbance in critically ill patients. Patients with higher APACHE II score at admission require more medications, catheters, and interventions which are important factors related to comfortable sleep.

Robust data collection, making cutoff for RCSQ and gathering information on patient's perception of sleep and related factors are the merits of our study. There are, however, important limitations to our study. A sample size of convenience was 
taken. The patients were not followed up by repeat actigraphy in ward or discharge, and therefore, the contribution of ICU admission to the sleep disturbance cannot be judged independently. We did not measure noise and light levels, dose, and duration of sedatives used, number of catheters and procedures carried out per patient per day; which would have helped us objectively assess risk factors and compare with other studies in the field. We assessed sleep quality as a dichotomous variable, although it occurs in continuum. Sleep staging was not possible through actigraphy, and therefore, it is unknown what the sleep distribution was. Other limitations for the use of actigraphy in ICU population include lack of validated criteria to define poor sleep. We need further studies with a larger sample size to validate actigraphy in ICU population and to determine the cutoff values of various actigraphy parameters.

\section{Conclusion}

There is a high prevalence of sleep disturbance among patients admitted to the ICU, especially those on MV. Knowledge about the factors related and designing methods to minimize these factors can help in improving quality of medical care and stay in ICU. Further studies are required to see whether poor sleep is associated with increased mortality and can effectively sleep avert such adverse outcomes.

\section{Financial support and sponsorship}

Nil.

\section{Conflicts of interest}

There are no conflicts of interest.

\section{RefEREnCES}

1. Collop NA, Salas RE, Delayo M, Gamaldo C. Normal sleep and circadian processes. Crit Care Clin 2008;24:449-60, v.

2. Tembo AC, Parker V, Higgins I. The experience of sleep deprivation in intensive care patients: Findings from a larger hermeneutic phenomenological study. Intensive Crit Care Nurs 2013;29:310-6.

3. Parthasarathy $\mathrm{S}$, Tobin MJ. Sleep in the Intensive Care Unit. Intensive Care Med 2004;30:197-206.

4. Friese RS, Diaz-Arrastia R, McBride D, Frankel H, Gentilello LM. Quantity and quality of sleep in the surgical Intensive Care Unit: Are our patients sleeping? J Trauma 2007;63:1210-4.

5. Helton MC, Gordon SH, Nunnery SL. The correlation between sleep deprivation and the Intensive Care Unit syndrome. Heart Lung 1980;9:464-8.

6. Grandner MA, Sands-Lincoln MR, Pak VM, Garland SN. Sleep duration, cardiovascular disease, and proinflammatory biomarkers. Nat Sci Sleep 2013;5:93-107.

7. Palmblad J, Cantell K, Strander H, Fröberg J, Karlsson CG, Levi L, et al. Stressor exposure and immunological response in man: Interferon-producing capacity and phagocytosis. J Psychosom Res 1976;20:193-9.

8. White DP, Douglas NJ, Pickett CK, Zwillich CW, Weil JV. Sleep deprivation and the control of ventilation. Am Rev Respir Dis 1983;128:984-6.

9. Salas RE, Gamaldo CE. Adverse effects of sleep deprivation in the ICU. Crit Care Clin 2008;24:461-76, v-vi.

10. Gabor JY, Cooper AB, Crombach SA, Lee B, Kadikar N, Bettger HE, et al. Contribution of the Intensive Care Unit environment to sleep disruption in mechanically ventilated patients and healthy subjects. Am J Respir Crit Care Med 2003;167:708-15.

11. Kamdar BB, Needham DM, Collop NA. Sleep deprivation in critical illness: Its role in physical and psychological recovery. J Intensive Care Med 2012;27:97-111.

12. BaHammam A. Sleep in acute care units. Sleep Breath 2006;10:6-15.

13. Elliott R, McKinley S, Cistulli P, Fien M. Characterisation of sleep in intensive care using 24-hour polysomnography: An observational study. Crit Care 2013;17:R46.

14. Krachman SL, D'Alonzo GE, Criner GJ. Sleep in the Intensive Care Unit. Chest 1995;107:1713-20.

15. Pisani MA, Friese RS, Gehlbach BK, Schwab RJ, Weinhouse GL, Jones SF, et al. Sleep in the Intensive Care Unit. Am J Respir Crit Care Med 2015;191:731-8.

16. Knauert MP, Yaggi HK, Redeker NS, Murphy TE, Araujo KL, Pisani MA, et al. Feasibility study of unattended polysomnography in medical Intensive Care Unit patients. Heart Lung 2014;43:445-52.

17. Sadeh A, Hauri PJ, Kripke DF, Lavie P. The role of actigraphy in the evaluation of sleep disorders. Sleep 1995;18:288-302.

18. Raj R, Ussavarungsi K, Nugent K. Accelerometer-based devices can be used to monitor sedation/agitation in the Intensive Care Unit. J Crit Care 2014;29:748-52.

19. Mistraletti G, Taverna M, Sabbatini G, Carloni E, Bolgiaghi L, Pirrone $\mathrm{M}$, et al. Actigraphic monitoring in critically ill patients: Preliminary results toward an "observation-guided sedation". J Crit Care 2009;24:563-7.

20. Grap MJ, Borchers CT, Munro CL, Elswick RK Jr., Sessler CN. Actigraphy in the critically ill: Correlation with activity, agitation, and sedation. Am J Crit Care 2005; 14:52-60.

21. Ely EW, Inouye SK, Bernard GR, Gordon S, Francis J, May L, et al. Delirium in mechanically ventilated patients: Validity and reliability of the confusion assessment method for the Intensive Care Unit (CAM-ICU). JAMA 2001;286:2703-10.

22. Netzer NC, Stoohs RA, Netzer CM, Clark K, Strohl KP. Using the berlin questionnaire to identify patients at risk for the sleep apnea syndrome. Ann Intern Med 1999;131:485-91.

23. Johns MW. A new method for measuring daytime sleepiness: The Epworth sleepiness scale. Sleep 1991;14:540-5.

24. Levey AS, Coresh J. Chronic kidney disease. Lancet 2012;379:165-80.

25. Schuiling WJ, Rinkel GJ, Walchenbach R, de Weerd AW. Disorders of sleep and wake in patients after subarachnoid hemorrhage. Stroke 2005;36:578-82.

26. Knaus WA, Draper EA, Wagner DP, Zimmerman JE. APACHE II: A severity of disease classification system. Crit Care Med 1985;13:818-29.

27. Moreno RP, Metnitz PG, Almeida E, Jordan B, Bauer P, Campos RA, et al. SAPS 3 - From evaluation of the patient to evaluation of the Intensive Care Unit. Part 2: Development of a prognostic model for hospital mortality at ICU admission. Intensive Care Med 2005;31:1345-55.

28. Richards KC, O'Sullivan PS, Phillips RL. Measurement of sleep in critically ill patients. J Nurs Meas 2000;8:131-44.

29. Kamdar BB, Shah PA, King LM, Kho ME, Zhou X, Colantuoni E, et al. Patient-nurse interrater reliability and agreement of the Richards-Campbell sleep questionnaire. Am J Crit Care 2012;21:261-9.

30. Sinha S, Gupta K, Tripathy S, Dhooria S, Ranjan S, Pandey RM, et al. Nevirapine- versus efavirenz-based antiretroviral therapy regimens in antiretroviral-naive patients with HIV and tuberculosis infections in India: A multi-centre study. BMC Infect Dis 2017;17:761.

31. Beecroft JM, Ward M, Younes M, Crombach S, Smith O, Hanly PJ, et al. Sleep monitoring in the Intensive Care Unit: Comparison of nurse assessment, actigraphy and polysomnography. Intensive Care Med 2008;34:2076-83.

32. Tryon WW. Issues of validity in actigraphic sleep assessment. Sleep 2004;27:158-65.

33. Cooper AB, Thornley KS, Young GB, Slutsky AS, Stewart TE, Hanly PJ, et al. Sleep in critically ill patients requiring mechanical ventilation. Chest 2000;117:809-18. 
34. Nicolás A, Aizpitarte E, Iruarrizaga A, Vázquez M, Margall A, Asiain C, et al. Perception of night-time sleep by surgical patients in an Intensive Care Unit. Nurs Crit Care 2008;13:25-33.

35. Myers BL, Badia P. Changes in circadian rhythms and sleep quality with aging: Mechanisms and interventions. Neurosci Biobehav Rev 1995;19:553-71.

36. Frisk U, Nordström G. Patients' sleep in an Intensive Care Unit - Patients' and nurses' perception. Intensive Crit Care Nurs 2003;19:342-9.
37. Bourne RS, Minelli C, Mills GH, Kandler R. Clinical review: Sleep measurement in critical care patients: Research and clinical implications. Crit Care 2007;11:226.

38. Gabor JY, Cooper AB, Hanly PJ. Sleep disruption in the Intensive Care Unit. Curr Opin Crit Care 2001;7:21-7.

39. Fanfulla F, Ceriana P, D'Artavilla Lupo N, Trentin R, Frigerio F, Nava S, et al. Sleep disturbances in patients admitted to a step-down unit after ICU discharge: The role of mechanical ventilation. Sleep 2011;34:355-62. 